\title{
Pre-service mathematics student teachers' conceptions of nominal and effective interest rates
}

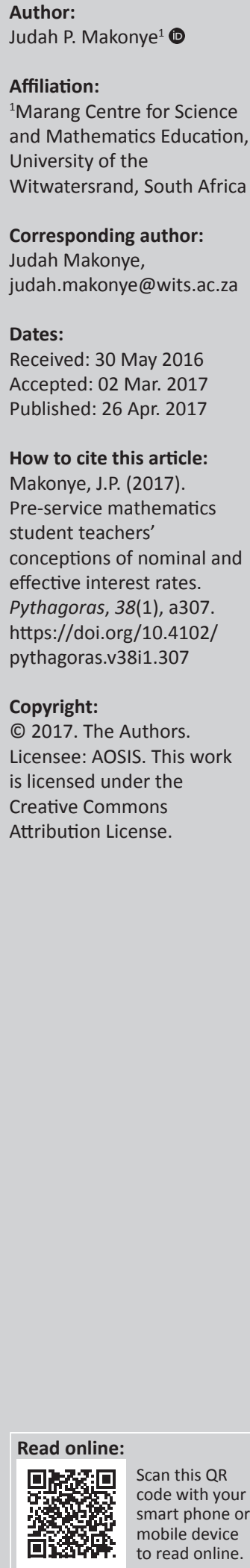

\begin{abstract}
The general public consumes financial products such as loans that are administered in the realm of nominal and effective interest rates. It is debatable if most consumers really understand how these rates function. This article explores the conceptions that student teachers have about nominal and effective interest rates. The APOS theory illuminates analysis of students' levels of conception. Seventy second-year mathematics students' responses to Grade 12 tasks on effective and nominal interest rates were analysed, after which 12 students were interviewed about their mathematical thinking in solving the tasks. The findings varied. While some students could not do the tasks due to erratic use of formulae (algebra), I ascertained that some students obtained correct answers through scrupulous adherence to the external prompt of formulae. Most of those students remained stuck at the action and process stages and could not view their processes as mathematical objects. A few students had reached the object and schema stages, showing mature understanding of the relationship between nominal and effective interest rates. As most students remained at the operational stages rather than the structural, the findings accentuate that when teaching this topic, teachers ought to take their time to build learners' schema for these notions. They need to guide their learners through the necessary action-process-object loop and refrain from introducing students to formulae too soon as this stalls their advancement to the object and schema stages which are useful in making them smart consumers of financial products.
\end{abstract}

\section{Introduction}

This article is about mathematics major student teachers' conceptions in the area of financial mathematics with particular reference to effective and nominal interest rates. Second-year mathematics major students' responses to Grade 12 financial mathematics tasks are analysed using the process of object theories (Dubinsky, 1991; Gray, Pitta \& Tall, 2000; Gray \& Tall, 1994; Piaget, 1985; Sfard, 1991; Tall, 2007). To help understand how students think about mathematics processes and objects, the author of this article, who is a lecturer to these students, uses this methodology to inform good preparation for teaching of student teachers.

Financial mathematics is not only an enriching mathematics topic in its own right, but it is also a topic of mathematics with practical applications in daily life for everyone. Yet many mathematics teachers do not understand the basics of this topic let alone how to teach it (Pournara, 2013). In this article I argue that exploring student teachers' conceptions of financial mathematics can help researchers and teachers to deal with key epistemological factors which could inform stakeholders to better handle mathematics topics in general and the financial mathematics topics in particular.

The nominal interest rate is the annual interest rate without any reference to compounding. The effective interest rate is derived from the nominal interest rate and yields the actual return on investment over a compounding period, which is often more than once per year; it could be halfyearly, quarterly, monthly or even daily. It is unusual to call a rate of interest a nominal rate unless it is compounded more (or less) frequently than once per annum.

Exploring students' epistemological difficulties through script analysis and interviews is an essential component of quality teaching (Makonye, 2012; Moru, Qhobela, Poka, \& Nchejane, 2014; Nesher, 1987). It is important because it informs researchers and practitioners about the difficulties experienced in specific mathematical processes and objects (Dubinsky, 1991; Gray et al., 2000; Gray \& Tall, 1994; Sfard, 1991) that mathematics learners encounter. Learners' conceptions provide their teachers with insight into their thinking, which can be used to inform teaching (Borasi, 1994; Gallagher, 2004). Their conceptions can reveal what they think about certain mathematical work. Pedagogical content knowledge (Shulman, 1986) constitutes the teacher's knowledge of the likely 
mistakes that learners are prone to when they encounter particular mathematical concepts as individuals or in groups. Pedagogical content knowledge is the interface between subject and pedagogical knowledge and is referred to as specialised content knowledge (Shulman, 1986), which refers to having the pedagogical knowledge to teach particular content to the learners. Shulman (1986) concludes that educators would not be effective if they were not knowledgeable about how learners form amateur concepts around particular scientific concepts (Vygotsky, 1986). Adler and Ball (2009) propose that mathematics knowledge for teaching is multidimensional and topic specific. Teachers with mathematical pedagogical content knowledge are more aware of learners' likely thinking patterns, which empowers them to introduce teaching interventions that help learners to learn mathematics more successfully. So teachers ought to establish learners' thinking patterns that produce errors. Teachers with pedagogical content knowledge can formulate situations that probe learners to elicit their erratic thinking on particular mathematical objects. This confrontation of learners with their misconceptions helps to induce cognitive conflict (Drews, Dudgeon, Hansen, Lawton \& Surtees, 2005). Once such misconceptions are manifested, teachers can devise pedagogical approaches to help learners understand that their thinking is in fact incomplete. For these reasons, it is important for mathematics teachers and their students to negotiate wrong conceptions as they inhibit mathematics learning.

Over the last three decades, many articles have been written on the misconceptions that learners show when learning mathematics (e.g. Cockburn \& Littler, 2008; Davis, 1984; Erlwanger, 1973; Green, Piel \& Flowers, 2008; Olivier, 1989; Shahrill, 2013). These articles report that the errors exhibited, whether shared or idiosyncratic, follow carefully reasoned patterns and are quite predictable, if one understands them. In particular, Olivier (1989), in his seminal paper, posits that the misconceptions are in the main due to 'patchwork' (p. 5), 'generalising over numbers' (pp. 6-7), 'generalising over operations' (p. 8), 'meanings' (p. 9) and 'interference' (p. 11). This implies that most misconceptions are formed as learners attempt to assimilate or accommodate new mathematical objects into their existing schema. Despite this research, there have been very few articles that explore student teachers' and teachers' misconceptions in school mathematics and how they form them. The conceptions that mathematics teachers' have are inadvertently passed on to learners even if incomplete or wrong. Further, teachers avoid teaching mathematics concepts about which they do not have enough knowledge.

\section{Objectives}

In relation to process-object theories of constructing mathematical concepts (Dubinsky, 1991; Gray \& Tall, 1994; Sfard, 1991), the research aims to explore the conceptions that teacher students majoring in mathematics have about the Grade 12 financial mathematics concepts of effective and nominal interest rates.

\section{Research question}

What are mathematics teacher students' conceptions of nominal and effective interest rates in relation to APOS and process-object theories?

\section{Significance of the research}

Since the onset of democracy, the average performance of South African learners on periodic international comparative mathematics tests has been consistently under expectation (Howie, 2001; Reddy et al., 2012). One would suspect that such attainment on the part of learners might not be wholly their fault. It might be that some of the teachers who teach these students are not necessarily more knowledgeable others in Vygotskian terms. Indeed, some mathematics teachers were recently requested to write their learners' Grade 12 mathematics examinations (Bansilal, Mkhwanazi \& Brijlal, 2014). They scored an average mark of $57 \%$ and a quarter of the teachers attained below 39\%. Similarly, many teacher students do not fully understand the school mathematics they teach. It is important to study how teacher students formulate the conceptions or misconceptions of mathematics that they have. The process-object theories help to explain how learners assimilate and accommodate new mathematical knowledge.

\section{Theoretical framework}

In this study, the process-object theories of forming mathematical structures inform the exploration of teacher students' conceptions about effective and nominal interest rates. According to Gilmore and Inglis (2008), these influential theories could be divided under three main views: the APOS theory (Arnon et al., 2014; Dubinsky, 1991); process-object theory (Sfard, 1991) and procept theory (Gray \& Tall, 1994).

Dubinsky (1991) and Arnon et al. (2014) propose a four-stage process of mathematics concept development (APOS) due to 'individuals' tendency to deal with perceived mathematical problems by constructing mental actions, processes, objects and organising these into schemas to make sense of the situations and solve problems' (Dubinsky, 1991, pp. 101-102).

\section{Action}

An action is a physical or mental transformation of a mathematical entity in response to outside stimuli. Actions may require initiation or mediation by a teacher or peer to direct steps that are explicitly taken towards a goal. It is the beginning stage of learning and making sense of a mathematical situation. Thus, an action conception leads to an operation external to a learner's mind.

\section{Process}

When an individual reflectively repeats an action they may interiorise it into a process. Interiorisation occurs when someone can carry out an action mentally. When someone reflects upon an action without actually engaging with it, 
they are said to have interiorised that action into a mental process (Aineamani, 2015; Cottril et al., 1996). When a mathematical entity is viewed as a process, it requires a computation to be done on that entity (Sfard, 1991). A process is operational and invokes the metaphor of a verb. A process conception leads to an operation internal to a learners' mind.

\section{Object}

When a mathematical entity is 'seen as an object' it is seen as if it were 'a real thing that exists in space and time' (Sfard, 1991, p. 4). As Aineamani (2015) explicates, 'a learner can be shown expressions such as $2 x+4$ and $7 x$ to show him/her the features that make an algebraic expression an object' (p. 60). A mathematical object is structural and invokes the metaphor of a noun. In real life, loans and loan purchases such as car loans and mortgages, bank savings, bond investments, inflation, depreciation and others governed by regular compounding of interest rates are mathematical objects in the sense of APOS theory.

According to Cottril et al. (1996), 'an object is constructed through the encapsulation of a process. ... [It] is achieved when the individual becomes aware of the totality of the process, realizes that transformations can act on it' $^{\prime}$ (p. 4). Thus when a process becomes an object, it becomes a thing, it achieves permanence, it becomes an entity in its own right; it has become a noun (Davis, 1984). Dubinsky (1991) refers to this transformation as the encapsulation of a process into an object. As Aineamani (2015) argues, 'reification (or encapsulation) enables the learner to see a familiar mathematical expression in a totally new light' (p. 61).

\section{Schema}

When actions, processes and objects are revisited and a learner has a bird's eye view of them, they form a schema of the mathematical entity. This schema is organically linked to other schemas. Analysis and reflection on a schema can generate yet another cycle of actions and processes so that new, more advanced mathematical objects and schemas can be formed.

If individuals can carefully compare financial products such as Mashonisa loans, Ponzi get-rich-quick schemes, bank loans, car loans and so on and make an informed decision, they have the schema on objects that are governed by nominal and effective interest rates. Individuals without this schema are in danger of losing out on their life's savings to schemers. The schemers do their mathematical calculations using nominal and effective interest rates very carefully to hide the disastrous financial effects for their unwary clients.

Dubinsky (1991) explains that when someone is developing the understanding of a mathematical idea, it does not necessarily happen in a linear process; rather, it is dialectic.

Similarly, Sfard (1991) argues that at first processes or operations are performed on a familiar object which is the interiorisation stage. At the second stage, referred to as condensation, the learner is able to reproduce the operation in their mind without actually doing it. At the third stage, if the learner suddenly sees the familiar process in new light; the process becomes a static structural object that can become the subject of even more advanced processes. Sfard refers to this as the reification of a process into an object.

Gray and Tall (1994) agree with the process-object theories of mathematics concept construction, but suggest that the movement from process to object and vice versa is enabled by a procept. They define an elementary procept as the 'amalgam of three components: a process which produces a mathematical object, and a symbol which is used to represent either process or an "object"' (p. 224). The procept is a mathematical symbol which often is a barrier to success in learning mathematics if students do not understand it (Gilmore \& Inglis, 2008). A major procept in this study is the nominal effective interest rate formula (see Figure 1).

But what really is the difference between mathematical processes and objects?

Sfard (1991) argues that processes focus on operations and procedures. In this research, finding the effective interest rate or the nominal interest rate using the formula shown in Figure 1 is a manipulation and therefore a process.

$$
1+i=\left(1+\frac{i^{(m)}}{m}\right)^{m}
$$

FIGURE 1: The nominal-effective interest rate formula.

In this formula (see Figure 1 ), $i$ is the effective interest rate, $i^{(\mathrm{m})}$ the nominal interest rate and $m$ the number of times interest is paid per annum.

Piaget (1985) argues that there are primarily two types of objects: (1) a physical one such as a triangle, which is visible, known as figurative or perceived objects, and (2) operative which cannot be seen, but can be only be thought of, such as the number 5. Piaget refers to these as conceived or operative objects. They exist because we can mentally do something with them.

Constructivists argue that learners are not explicitly taught the misconceptions they have, but make them by themselves (Confrey \& Kazak, 2006; Davis, 1984). Since learning does not occur in a vacuum, students' conceptions, however mistaken, are the result of their reigning knowledge with which they connect and interpret new knowledge. If new knowledge is connected to current knowledge that is incorrect, another error will occur. In addition, even if reigning knowledge is correct, problems can result while connecting it to new knowledge. New knowledge has to be integrated with something a learner already knows, however tenuous.

Behaviourist learning theories (McLeod, 2007; Todes, 2002) view students' conceptions that are errors as pernicious in the learning process. Their stance is that once detected, errors 
must be weeded out and corrected to make them extinct. On the other end of the spectrum, constructivists view errors as useful resources in teaching and learning mathematics (Borasi, 1994; Nesher, 1987). They regard errors as learners' attempts to construct meaning from a learning context. To constructivists, once a learner shows an error, the teacher must be strategic about it. They must refrain from immediately supplying a correct answer as this would be missing a learning opportunity for the learner. Rather, the teacher needs to help the learner to reconsider their positions by requesting the learner to compare their answers with those of their peers. That way, the learners encounter peer-induced cognitive conflict which can help them to reconcile their thinking.

According to Davis (1984), a student's thinking that results in errors is not random; on the contrary, errors turn out to be very regular and systematic. They have specificity and determinism and it is often possible to predict exactly which wrong answer is most likely to be given by a particular student. So systematic wrong answers given by a student often provide clues as to how the student is thinking about a class of mathematical processes and objects. According to Davis, students use frames they have to interpret and process new knowledge. Assimilating new knowledge in old frames is often problematic as the frames might be overstretched to generalise to new platforms on which they are not appropriate.

\section{Methodology}

The research used a qualitative research design. Eisner (1991) proposes that a good qualitative study assists to 'understand a situation that would otherwise be enigmatic or confusing' (p. 58). At first the teacher students wrote tasks on nominal and effective interest rates which required them to do calculations as well as offer written explanations regarding the differences between those interest rates (see Appendix 1). Then, some were interviewed about their notions of nominal and effective interest rates to support their answers. Seventy second-year mathematics major students of both genders were given previous years' Grade 12 financial mathematics examination tasks on effective and nominal interest rates. Their scripts were collected and responses analysed.

Students' responses to tasks were first analysed under the categories of correct, partially correct and incorrect, as well as not attempted. After this, 12 student teachers were interviewed in pairs to elicit the thinking behind their responses, whether the responses were correct or wrong. The students chosen for interview constituted a stratified sample by performance and gender. The interviews were analysed so that the stages where students faltered in concept formation could emerge.

\section{Reliability and validity}

To ensure reliability of the research, data were collected through both written tasks and interviews. This allowed for probing of students in the interviews to see if they stuck to their written answers and to determine their thinking on nominal and effective interest rates. There was also internal consistency reliability to assess the degree to which different tasks involving the same concept produced comparable results (see Appendix 1).

Construct validity helps to guarantee that the measure essentially measures the intended construct, in this case students' conceptions on nominal and effective interest rates. This was the most important form of validity in this research. I selected nominal and effective interest rate tasks from 2012 and 2013 Mathematics matric examinations as well as from textbooks approved by the Department of Basic Education. This increased the face validity of the research.

To be faithful to the theoretical framework, students' responses in scripts and interviews were analysed focusing on whether the conceptions found were at the action, process, object or schema stages of concept formation or in transition between one stage and another. Thus, teacher students' conceptions were analysed through the lens of how they constructed knowledge with the process to object constructions.

\section{Data analysis}

Data were analysed both deductively and inductively. Deductive analysis was informed by the APOS framework for building mathematics knowledge. Inductive analysis occurred through grounded theory. Grounded theory is a continuous process of 'constant comparison' (Glaser \& Strauss, 1973, p. 36) to come up with categories and themes underpinning the data. This happens through de-contextualising and recontextualising data to come up with meanings that help to answer the research questions.

When students were given written tasks on effective and nominal interest rates, the work was marked and their performance is shown in graphs (see Figure 2 and Figure 3).

Figure 2, Figure 3 and Table 1 show that the performance for the students on the written tasks was wanting. In all cases

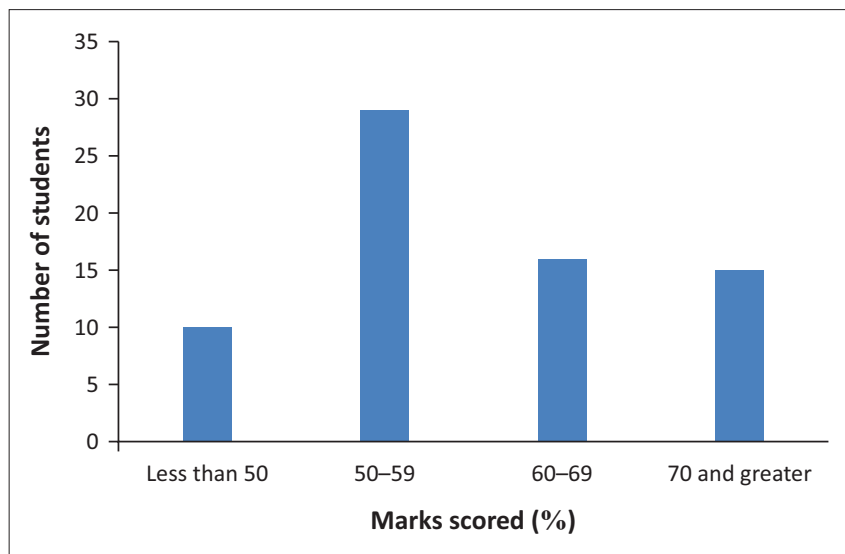

FIGURE 2: Percentage performance of teacher students on nominal and effective rate tasks. 


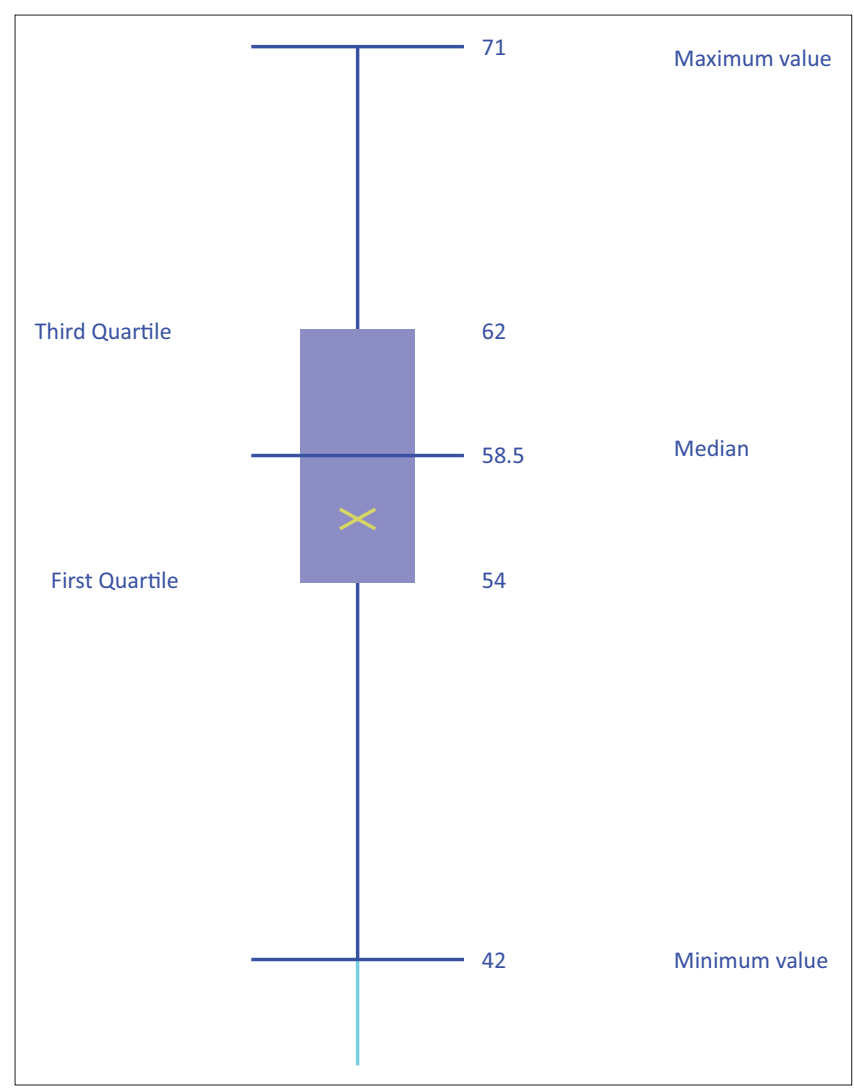

FIGURE 3: Boxer and whisker plot for teacher students' performance.

TABLE 1: Some statistics on students' performance on the tasks.

\begin{tabular}{ll}
\hline Characteristics & Number \\
\hline Population size & 70 \\
Median & 58.5 \\
Modes & 57.60 and 62 \\
Mean & 57.3 \\
Minimum & 31 \\
Maximum & 71 \\
First quartile & 54 \\
Third quartile & 62 \\
Interquartile range & 8 \\
Standard deviation & 7.9 \\
\hline
\end{tabular}

the mean mark per item was lower than half the possible mark. This is the reason why it was important to probe and elicit students' conceptions of the constructs under question in light of the APOS theory.

I now briefly analyse some written work.

One of the items was:

Question 2: Mrs Ndlovu invested R10 000 in the bank with interest compounding monthly. After one year, she had R10 750 in the bank. Calculate 2.2 the effective interest rate and 2.3 the nominal interest rate.

For calculating effective interest rate one student wrote:

$\log 1.075=\log \left(1+\frac{i}{12}\right)^{12}$
This emanates from the following formula:

$F V=P(1+r / n)^{Y n}$

$P$ is the present value, $r$ is the nominal interest rate, $Y$ is the number of years invested, $n$ is the number of compounding periods per year and $F V$ is the amount the present value accumulates to in $Y$ years.

The student used formulaic reasoning. Given that R10 000 grew to R10 750 in one year, there was no need to go the formula way. They should have used the object stage thinking that R750 interest was earned on a principal of R10 000, so the effective interest rate must have been $7.5 \%$. Thus the student was operating at the action level where they used the formula as a way to process external stimuli.

The substitution was quite correct if they wanted to find the nominal interest rate, but then the student divided on both sides by ' $\log ^{\prime}$ as if ' $\log$ ' was an algebraic variable representing a number so that it can be 'cancelled':

$\frac{\log (1.075)}{\log }=\left(1+\frac{i}{12}\right)^{12}$

$1.075=\left(1+\frac{i}{12}\right)^{12}$

This was a conception of equation balancing, prefaced by the rule 'you do the same thing to both sides of an equation and they are still equal' (Pimm, 1987, p. 20). I regard this conception as at action level. Students who do not fully understand the limits of formulae are at the action stage, not having interiorised it into a process.

In trying to answer the same item, some students mixed up the periods, for example $1.075=\left(1+\frac{i}{4}\right)^{12}$, in this case quarterly interest rates (denoted by the number 4) and monthly payments (denoted by the number 12). This is a failure to operate at action level. Improper action level performances are made. Students do not understand the use of the formula, how to choose its input variables, the time and interest rates per period, so that they can process properly.

Some students seemed to have proper action and process conceptions as evidenced by correct answers found through use of the formula. However, I wished to be convinced whether they had formed in their minds permanent objects or schemas of nominal and effective interest rates. Such doubts could only be laid to rest through interviews. I sat in a classroom and interviewed students (see Box 1).

Participant $\mathrm{N}$ is confused as she thinks that if the interest is stated once per year then it must be nominal. She is at the action level of conception as she clearly states that she sticks to the formula. Her interpretation that the nominal interest rate is $7.25 \%$ is purely directed by her faith in the formula. 
To her, the formula seems to be the 'object' - the end in itself which really is not the case. Participant $\mathrm{N}$ clearly shows that her mathematical thinking on these concepts is governed by formulae - ends in themselves - but she is clearly unhappy because she complains that any mistake in the substitutions leads to disaster (see Box 2).

Participant $\mathrm{S}$ thinks the interest rates are different because they have different formulae. That means that she is at the action conception level. She has not yet interiorised the actions into processes. To her they are different 'objects' because they look different not because they essentially would earn different amounts of interest at the end of the year (see Box 3).

While Participant Q's responses are not much different from the other students, Participant $\mathrm{R}$ said the 'effective interest rate is better because it is more reliable'. This he said even though the effective interest rate yielded the same interest amount as the nominal interest rate. Clearly his view is a belief. At the end of the interview with this pair, he said, 'Most banks give nominal, others give effective interest rate.
The reason is to protect them from liability.' This was an important remark, but it was clear that he could not say why the effective interest rate protects these banks from liability. He also said, 'Effective tells you how much you get each month (error). Nominal you get it once a year.' This pair was very cooperative but though they had correct numerical answers they still held an action conception of these concepts. I did not see the 'Aha!' I was anticipating by doing this interview with these good students (see Box 4).

Clearly Participant T had achieved the object and schema conception level I was looking for (see Box 5).

Participant $\mathrm{Y}$ and Participant $\mathrm{K}$ did not rely on formulae; they used common sense as we were speaking to each other. They never, unlike Participant $Q$ and Participant $R$, clutched for their bags to look for formulae from books or calculators when asked a question. To me they had reached schematic conception of nominal and effective interest rates. This is because they had interiorised the actions to processes and encapsulated the processes to objects. They were willing to revisit their conceptions and did not regard them as fixed;

BOX 1: Participant N and Participant P.

\begin{tabular}{|c|c|}
\hline Researcher & How do you understand the difference between nominal and effective interest rate? \\
\hline Participant N & $\begin{array}{l}\text { I do not fully understand this with ... effective. Nominal ... when you get interest after } 12 \text { months. Effective; monthly, daily interest obtained. Effective } \\
\text { interest rate you get more. }\end{array}$ \\
\hline Researcher & How is nominal compounded monthly? \\
\hline Participant N & I just stick to the formula. \\
\hline Researcher & Explain what you did on 2 . \\
\hline Participant N & I just used the formula but I did not understand. I try to understand it but I can't lie. I don't. I am senior primary specialist. \\
\hline Researcher & And the difference between effective and nominal interest? \\
\hline Participant P & $\begin{array}{l}\text { In nominal it's fixed in a period of time; will remain the same. Effective interest rate accumulates over time directed by the nominal. The accumulated } \\
\text { interest is the effective rate. }\end{array}$ \\
\hline Researcher & Is the effective rate fixed? \\
\hline Participant P & The effective rate will change, as the years increase the effective rate increases. The knowledge that the effective rate is more than the nominal helps. \\
\hline Participant N & $\begin{array}{l}\text { For me it was effective [referring to } i=7.25 \% \text {. that she found by } 10750=10000\left(1+\frac{i}{12}\right)^{12} \text { ]. It was actually nominal. Nominal, you only get it once at the } \\
\text { end of the year. }\end{array}$ \\
\hline Participant P & Effective rate is an accumulation of compounding period. Interest accumulated is the effective. Does not have a fixed period. \\
\hline Participant N & The most difficult part of financial maths is defining difference between nominal and effective interest rates. \\
\hline Participant N & $\begin{array}{l}\text { Formulae do not allow you to think outside the box. We think that the formula that are given must be used for all the question ... sometimes you forget the } \\
\pm \text { sign in a formula ... minus should be there ... sometimes it should be }+.\end{array}$ \\
\hline Researcher & Does effective interest rate change over years? \\
\hline Participant N & I think it changes. \\
\hline
\end{tabular}

Participant N, female student; Participant $\mathrm{P}$, male student.

BOX 2: Participant S.

\begin{tabular}{|ll|}
\hline Researcher & What is the difference between effective and nominal interest rates? \\
Participant S & $\begin{array}{l}\text { Effective interest compounded monthly rate will be better as opposed to nominal interest rate of a year, because you get more. Nominal is over one year, } \\
\text { and effective is compounding monthly. We distinguish between the two because they are different rates. They are different because there are two different } \\
\text { formulas for that. }\end{array}$ \\
\hline $\begin{array}{l}\text { Researcher } \\
\text { Participant S }\end{array}$ & So... \\
Researcher & Yes... \\
\hline Participant S & $\begin{array}{l}\text { Well I can't calculate the interest rate. [Looks for a book in the bag to get a formula from a past matric textbook in her bag. The student would have rather } \\
\text { figured the answer.] [After working] Nominal is } 12 \% \text { and effective is } 12.7 \% .\end{array}$ \\
Researcher & And why are there different? \\
Participant S & I do not know why they are different. I used formula from high school. I do not know the difference between the two. \\
\hline
\end{tabular}

Participant $\mathrm{S}$, female student. 
BOX 3: Participant $Q$ and Participant $R$.

\begin{tabular}{|c|c|}
\hline Researcher & What is the difference between effective and nominal interest rates? \\
\hline Participant Q & I don't really remember. \\
\hline Researcher & Why do we need the two? \\
\hline Participant Q & With effective you compound every month but nominal it's once. \\
\hline Participant R & $\begin{array}{l}\text { Nominal does not depend on compounding. When we had research on interest rates, I wasn't sure of the difference between the nominal and effective } \\
\text { interest rates. I do not know the difference. We just work it out ... we just work it out. }\end{array}$ \\
\hline Researcher & Look at the question. \\
\hline Participant Q & Nominal is $12 \%$. I don't remember the formula. Effective is $12 \%$. I guessed the answer. \\
\hline Participant R & $\begin{array}{l}\text { Nominal is } 12 \% \text {, effective is } 12 \% \text { [here the student used a formula]. } \\
\text { [Comment: I see here that Participant R understands the question.] }\end{array}$ \\
\hline Researcher & So which investment is better between; $12 \%$ p.a. nominal versus $12 \%$ effective annual? \\
\hline $\begin{array}{l}\text { Participant } \mathrm{R} \text { and } \\
\text { Participant } \mathrm{Q}\end{array}$ & $12 \%$ effective is better because its more reliable. \\
\hline
\end{tabular}

Participant $\mathrm{Q}$, male student; Participant $\mathrm{R}$, male student.

BOX 4: Participant T.

\begin{tabular}{|ll|}
\hline Researcher & What is the difference between effective and nominal interest rates? \\
\hline Participant T & Effective is the actual interest you will be given. Nominal is the stated. If nominal is $12 \%$ stated, the effective could be a little more than $12 \%$. \\
Researcher & $12 \%$ p.a. nominal versus $12 \%$ effective annual, which is better? \\
\hline Participant T & Hoo ... the effective is the same ... will be the same as the nominal. If it's more than one year, then the effective will be more. \\
\hline
\end{tabular}

Participant T, male student.

BOX 5: Participant $Y$ and Participant $K$.

\begin{tabular}{|c|c|}
\hline Researcher & What is the difference between effective and nominal interest rates? \\
\hline Participant K & The effective I think is compounded many times. \\
\hline Participant $Y$ & $\begin{array}{l}\text { I can't remember the difference, but one is done monthly and the other quarterly. } \\
\text { Monthly, you pay interest every month. } \\
\text { The effective is better, I am thinking of the equation. The effective gives more interest because it's compounded more. }\end{array}$ \\
\hline Participant $Y$ & You said it could be $10 \%$. The calculation seems right. \\
\hline Researcher & $12 \%$ p.a. nominal versus $12 \%$ effective annual, which is better? \\
\hline
\end{tabular}

Participant K, female student; Participant $Y$, female student.

this is exemplified by Participant Y saying 'I have no idea but you get the same....' Her conceptions came out as appropriate even when she said she was not too sure.

\section{Ethical consideration}

Ethical approval of the research was obtained from the Ethics Committee in Education of the Faculty of Humanities acting on behalf of the University Senate. After obtaining approval each participant gave their written informed consent to participate in the research. They also gave informed consent for the publication of the research in a research journal. In particular the students were keen to see the research published so that it would help them in preparing to teach the topic of nominal and effective interest rates.

\section{Discussions and conclusions}

Statistical data on performance on nominal and effective interest rate tasks (see Figure 2 and Figure 3) show that some teacher students had not made adequate advances on the APOS stages (Arnon et al., 2014; Dubinsky, 1991) in constructing appropriate conceptions. Script analysis and interview data show that students' stages for understanding effective and nominal interest rates sometimes shifts; it moves back and forth often between the action and process conceptions as proposed by Dubinsky (1991). While some teacher students reached the object and schema stages of concept formation on nominal and effective interest rates many others were at action level, and a few at the process level. In their productions, students were mainly aided by the procept (Gray \& Tall, 1994) of the formula that connects actions, processes and objects. This manifested in the interviews where the same students responded with objectbased thinking as well as process-based and action-based thinking on the same task. For example, Participant R (and Participant Q) said 'I do not know the difference [between nominal and effective interest rates] ... I just work it out', which is action-based thinking. At the same time they said 'we just work it out...we just work it out. ... 12\% effective is better because it's more reliable', which seems both object-based and action-based thinking. Trying to interpret this further Participant $Q$ had not really reached object level conception as he could not justify it.

On investigating and assessing students' written and interview responses to effective and nominal interest rates tasks, four categories of students' conceptions emerge. The first category consisted of students who failed to get correct answers because they could not scrupulously use the formula in order to obtain correct answers. Thus these students failed 
to operate at the processes stage; they had not interiorised the actions (Dubinsky, Weller, McDonald \& Brown, 2005; Sfard, 1991) so they were at the lowest action stage. The second group of students was quite scrupulous and meticulous in using their formulae, which resulted in them obtaining correct answers. However, on interviewing some of these students I realised that they were fixated at the process stage in that when asked to explain or demonstrate their understanding of effective and nominal interest rates they showed clearly that they had not reached the object level of conception and were comfortably poised at the process stage. They thus have interiorised the action but not yet condensed and reified the process into an object, a standalone mathematical entity (Sfard, 1991). A third, but tiny, group of students operated at the object level of understanding in that when asked to explain the difference between the effective and nominal interest rates they never considered using their calculators, but just reasoned and verbalised their conceptions. This was in contrast with the second group who were quick to grab their calculators and textbooks to get the formula in order to the answer the same questions. The rest of the discussion expands these categories. There was also a fourth category with very few students.

\section{Category 1: Activity conceptions}

In this category, blind and erratic substitution into financial mathematics formulae was common. Participant $\mathrm{N}$ and Participant $S$ fall in this category. For example, Participant $N$ said 'sometimes you forget the \pm sign in a formula ... minus should be there ... sometimes it should be plus' and added 'the most difficult part of financial maths is defining the difference between nominal and effective interest rates.' One would assume that students like Participant N would have difficulty in using the formula and as a result get wrong answers. These students are still at the activity level (Dubinsky et al., 2005). Other practitioners strongly believe that if a learner cannot use a formula to correctly get an answer, they have not reached the activity level. I think some learners who cannot manipulate the formula may actually be at the object level, reasoning that more frequent interest payments result in the effective rate paying out more interest than the nominal interest rate. Such students may have difficulties in aligning the formula in terms of time and periodic interest rates to substitute in the formula. That is why one cannot always be absolutely sure that a student is operating at a particular APOS stage.

\section{Category 2: Process conceptions}

These are the students who got correct answers for wrong reasons. These students were satisfying the ritual of getting the correct answers to get the approval of their teachers and getting good grades but without understanding the gist of what they were doing. Many of these students got correct answers through using formulae they did not understand. Examples of these students are Participant $\mathrm{R}$ and Participant $\mathrm{Q}$ (see Box 3). Participant $\mathrm{S}$ was at the process stage, when referring to the different interest rates, she said 'they are different because there are two different formulas for that'.

\section{Category 3: Object conceptions}

These were the few students who actually had achieved the object of learning conception. They had already encapsulated the processes into objects ready to incorporate them in their schemas. For example, on item 2:

Researcher: What is the difference between effective and nominal interest rates?

Participant T: Effective is the actual interest you will be given. Nominal is the stated. If nominal is $12 \%$ stated, the effective could be a little more than $12 \%$

So Participant $\mathrm{T}$ operated at object level. He completely understood and gave reasons for his stance.

Participant Y said, 'The effective is better, I am thinking of the equation. The effective gives more interest because its compounded more.' Participant $\mathrm{Y}$ also had arrived at this level. Participant P also understands as he said, 'In nominal ... it's fixed in a period of time; will remain the same. Effective interest rate accumulates over time directed by the nominal. The accumulated interest is the effective rate.'

\section{Category 4: Schema conceptions}

Students like Participant T and Participant $\mathrm{Y}$ had clearly arrived at the schema stage of conception. This was shown in their brightly lit eyes, and their exclamations of 'Hoo'. They knew what was happening and the traps that lay in the questions.

The research question was: What are mathematics teacher students' conceptions of nominal and effective interest rates in relation to APOS and process-object theories?

I report that most teacher students are at the action conception on these concepts and seem unaware that their conceptions are unsatisfactory and incomplete. They need to advance their conceptions to the desirable object and schema stages. The fact that formulae help them to get correct answers seems to stall their efforts to learn more. Thus, most teacher students in this research showed that their understanding is operational (at action or process stages) rather than structural (at object or schema stages) (Sfard, 1991). The operational conception is indicated by the increased amount of time they spend on solving tasks with the use of calculators and formulae compared to those students who use object-based strategies. Much fewer teacher students in this research have object and schema conceptions on nominal and effective interest rates. Gilmore and Inglis (2008) have shown that object-based thinking is more economical and more powerful than process-based thinking. This is also shown in this research as object-based teacher students used discourse to come up with balanced reasons for their positions. 


\section{Implications and recommendations}

Some students said to me: 'at school we were just given formulae'. This suggests that some of the students' incomplete conceptions result from teachers who want learners to obtain answers quickly, and are not concerned about developing the lasting and more powerful object and schema conceptions. The implication for teaching mathematics of this is that teachers must not rush to introduce calculators and formulae to learners when they are teaching nominal and effective interest rates. This hinders learners from constructing the object and schema conceptions which are the ultimate goals for teaching these topics, in order for learners to be financially literate. Rather, teachers must encourage their learners to learn about these concepts inductively, through engaging in numerical investigations and exercises that help to make the APOS constructions. Practical real-life street investigations on loans and loan products (e.g. Mashonisa loan sharks versus bank loans, Ponzi schemes, fixed deposit savings and others) go a long way in developing mature conceptions related to nominal and effective interest rates in mathematics teacher students.

The recommendations are that more studies be done on how the APOS theory may be used for research in financial mathematics education.

\section{Acknowledgements}

My special thanks go to my colleagues Marie Weitz and Bharti Pharshotam for encouraging me to do the research and for reading drafts of this manuscript.

\section{Competing interests}

The author declares that he has no financial or personal relationships that may have inappropriately influenced him in writing this article.

\section{References}

Adler, J., \& Ball, D. (2009). Knowing and using mathematics in teaching. For the Learning of Mathematics, 29(3), 2-3.

Aineamani, B. (2015). Teaching algebra with understanding. In S. Maoto, B. Chigonga, \& K. Masha (Eds.), Proceedings of the 21st Annual National Congress of the Association for Mathematics Education of South Africa (AMESA) (Volume 1, pp. 57-68). Polokwane, RSA: AMESA.

Arnon, I., Cottrill, J., Dubinsky, E., Oktac, A., Fuentes, S.R., Trigueros, M. et al. (2014) APOS theory: A framework for research and curriculum development in mathematics education. New York, NY: Springer.

Bansilal, S., Mkhwanazi, T., \& Brijlall, D. (2014). An exploration of the common content knowledge of high school mathematics teachers. Perspectives in Education, 32(1), 34-50.

Borasi, L. (1994). Capitalizing on errors as "springboards for inquiry": A teaching experiment. Journal for Research in Mathematics Education, 25(2), 166-208.

Cockburn, A., \& Littler, G. H. (2008). Mathematical misconceptions: A guide for primary teachers. Los Angeles: SAGE.
Confrey, J., \& Kazak, S. (2006). A thirty-year reflection on constructivism in mathematics education in PME. In P. Boero, \& A. Gutierrez (Eds.), Handbook of research on the psychology of mathematics education: Past, present and future research on the psychology of mathematics
(pp. 305-345). Rotterdam: Sense Publishers.

Cottrill, J., Dubinsky, E., Nichols, D., Schwingendorf, K., Thomas, K., \& Vidakovic, D. (1996). Understanding the limit concept: Beginning with a coordinated process scheme. Journal of Mathematical Behavior, 15, 167-192.

Davis, R.B. (1984). Learning mathematics: The cognitive science approach to mathematics education. Norwood, NJ: Ablex Publishing Corporation.

Drews, D., Dudgeon, J., Hansen, A., Lawton, F., \& Surtees, L. (2005). Children's errors in mathematics: Understanding common misconceptions in primary schools. Exeter, UK: Learning Matters.

Dubinsky, E. (1991). Reflective abstraction in advanced mathematical thinking. In D.O. Tall (Ed.), Advanced mathematical thinking (pp. 95-126). Dordrecht: Kluwer.

Dubinsky, E., Weller, K., McDonald, M., \& Brown, A. (2005). Some historical issues and paradoxes regarding the concept of infinity: An APOS-based analysis: Part 1. Educational Studies in Mathematics, 58, 335-359.

Eisner, E.W. (1991). The enlightened eye: Qualitative inquiry and the enhancement of educational practice. New York, NY: Macmillan Publishing Company.

Erlwanger, S.H. (1973). Benny's conception of rules and answers in IPI mathematics. Journal of Children's Mathematical Behavior, 1(2), 7-26.

Gallagher, D. (2004). The importance of constructivism and constructive pedagogy for disability studies in education. Disability Studies Quarterly, 24(2), 1-15.

Gilmore, C., \& Inglis, M. (2008, July 17-21). Process and object based thinking in arithmetic. In O. Figueras et al. (Eds.), Proceedings of the 32nd Conference of the International Group for the Psychology of Mathematics Education (Vol. 3. PME 32, pp. 73-80). Morelia, Mexico: PME.

Glaser, B.G., \& Strauss, A. L. (1973). The discovery of grounded theory: Strategies for qualitative research. Mill Valley: Sociology Press.

Gray, E.M., Pitta, D., \& Tall, D.O. (2000). Objects, actions, and images: A perspective on early number development. Journal of Mathematical Behavior, 18(4), 401-413.

Gray, E.M., \& Tall, D.O. (1994). Duality, ambiguity, and flexibility: A "proceptual" view of simple arithmetic. Journal for Research in Mathematics Education, 26(2), 115-141.

Green, M., Piel, J., \& Flowers C. (2008). Reversing education majors' arithmetic misconceptions with short-term instruction using manipulatives. Charlotte, NC Heldref Publications.

Howie, S. (2001). Mathematics and science performance in grade 8 in South Africa 1998/99: TIMMS-R 1999 South Africa. Pretoria: Human Sciences Research Council.

Makonye, J.P. (2012). Learner mathematical errors in introductory differential calculus tasks: A study of misconceptions in the senior school certificate examinations. Unpublished doctoral dissertation, University of Johannesburg South Africa.

McLeod, S.A. (2007). B.F. Skinner: Operant conditioning-simply psychology. Retrieved 04 May, 2016, from http://www.simplypsychology.org/operant-conditioning.html

Moru, E.K., Qhobela, M., Poka, W., \& Nchejane, J. (2014). Teacher knowledge of error analysis in differential calculus. Pythagoras, 35(2), 263-273.

Nesher, P. (1987). Towards an instructional theory: The role of learners' misconception for the learning of mathematics. For the Learning of Mathematics, 7(3), 33-39.

Olivier, A. (1989). Handling pupils' misconceptions. Pythagoras, 21, 10-19.

Piaget, J. (1985). The equilibrium of cognitive structures: The central problem of intellectual development. Chicago, IL: University of Chicago Press.

Pimm, D. (1987). Speaking mathematically. London: Routledge.

Pournara, C. (2013). Teachers' knowledge for teaching compound interest. Pythagoras, $34(2), 1-10$

Reddy, V., Prinsloo, C., Visser, M., Arends, F., Winnaar, L., \& Rogers, S. (2012). Highlights from TIMSS 2011: The South African perspective. Pretoria: HSRC.

Sfard, A. (1991). On the dual nature of mathematical conceptions: Reflections on processes and objects as different sides of the same coin. Educational Studies in Mathematics, 22, 1-36.

Shahrill, M. (2013). Clustering of decimal misconceptions in primary and secondary classes. International Journal of Humanities and Social Science, 3(11), 58-65.

Shulman, L. (1986). Those who understand: Knowledge growth in teaching. Educational Researcher, 15(2), 4-14.

Tall, D.O. (2007). Developing a theory of mathematical growth. ZDM: The International Journal on Mathematics Education, 39, 145-154.

Todes, D.P. (2002). Pavlov's physiology factory. Baltimore, MD: Johns Hopkins University Press.

Vygotsky, L. (1986). Thought and language. Cambridge, MA: MIT Press. 


\section{Appendix 1}

Written tasks

1. James invested $R 50000$ in the bank for 1 year. The nominal interest rate was $8,5 \%$. Find the effective rate. (3)

2. Mrs Ndlovu invested R10 000 in the bank with interest compounding monthly. After one year, she had R10 750 in the bank.

2.1. What can you say about the effective and nominal interest rates here?

Calculate:

2.2. the effective interest rate (2)

2.3. the nominal interest rate (3)

\section{Interview questions}

1. What is nominal interest rate?

2. What is effective interest rate?

3. Why do we need to distinguish between the two?

4. What is the difference?

5. Someone invests R1000 for a duration of one year and is awarded an interest of R120.

a. What is the annual nominal interest rate?

b. What is the annual effective interest rate?

c. In the above case, the R1000 was deposited at $r \%$ compounded monthly. Which would be a better investment, the one with the annual nominal interest rate or the own with the interest rate that was compounded monthly? 